\title{
Effects of acute exercise on high density lipoprotein cholesterol and high density lipoprotein subfractions in moderately trained females
}

\author{
P M Gordon, S Fowler, V Warty, M Danduran, P Visich, S Keteyian
}

School of Medicine, West Virginia

University

P M Gordon

Department of Human Performance, Mankato State University

S Fowler

Department of Clinical Chemistry, University of Pittsburgh

V Warty

Lutheran General Hospital, Chicago, IL M Danduran

Human Performance, Central Michigan

University, Detroit, MI

P Visich

Henry Ford Hosptial, Detroit, MI, USA

S Keteyian

Correspondence to: Dr P M Gordon, West Virginia University School of Medicine, Division of Exercise Physiology, PO Box 6116, Morgantown, WV 26506-6116, USA.

Accepted for publication 28 July 1997

\begin{abstract}
Increases in high density lipoprotein cholesterol (HDL-C) levels have previously been reported after moderate exercise bouts lasting less than two hours in men. Little information exists, however, on HDL-C responses after moderate duration exercise in women. Post-exercise HDL-C modifications may appear differently in women because of higher baseline HDL-C concentrations and differences in lipolytic activity. To determine the influence of exercise on acute HDL-C responses in women, 12 trained premenopausal women (22 (4) years old; mean (SD)) who ran 24-48 km a week exercised on a motor driven treadmill at $\mathbf{7 5 \%}$ Vo, MAX until 3.34 MJ (800 kcal) were expended (72 (9) $\mathrm{min})$. Subjects were all tested during the early follicular phase of their menstrual cycle. Fasting blood samples were obtained before exercise (baseline), immediately after (IPE), one hour after (1 h PE), 24 hours after (24 h PE), and 48 hours after (48 h PE) exercise. Plasma was analysed for HDL-C, $\mathrm{HDL}_{2}-\mathrm{C}$, and $\mathrm{HDL}_{3}-\mathrm{C}$. A significant increase in HDL-C was observed $48 \mathrm{~h}$ PE $(p<0.05)$. $\mathrm{HDL}_{3}-\mathrm{C}$ increased IPE $(p<0.01)$ but returned to baseline at $1 \mathrm{~h} \mathrm{PE}$. In contrast, $\mathrm{HDL}_{2}-\mathrm{C}$ was not significantly different from baseline at any time point. The rise in HDL-C, however, was attributed to an increase in both $\mathrm{HDL}_{2}$ and HDL $_{3}$. Moreover, at $48 \mathrm{~h}$ PE, the increase in HDL-C correlated highly with changes in $\mathrm{HDL}_{2}-\mathrm{C}(r=0.92)$. Thus it appears that exercise of moderate duration can elicit similar post-exercise increases in HDL-C in women to those previously reported in men. However, the changes in HDL subfractions leading to the rise in HDL-C may be different in women.

(Br f Sports Med 1998;32:63-67)
\end{abstract}

Keywords: women; lipids; high density lipoprotein; cholesterol; exercise; physical activity

Risk for coronary heart disease is inversely related to serum concentrations of high density lipoprotein cholesterol (HDL-C). ${ }^{12}$ Habitual exercise training reduces the risk of coronary heart disease, in part, through an increase in HDL-C. ${ }^{3}$ Similarly, some of the HDL-C modifications observed with endurance training can be partially induced from a single exercise bout. ${ }^{4-6}$ Previous investigations have identified increases in HDL-C after protracted endurance events such as a marathon or triathlon in men, ${ }^{78}$ women, ${ }^{910}$ or both. ${ }^{11}$ However, investigations using shorter exercise bouts (less than two hours) have yielded equivocal results, in part, because of the lack of control for potentially confounding variables. ${ }^{3}$

Post-exercise HDL-C responses may be influenced by diet composition, training status, baseline HDL-C, a previous bout of exercise, and lack of or an incomplete estimation of plasma volume shifts. ${ }^{3}$ When these extraneous variables were controlled, increases in HDL-C after shorter exercise bouts were observed in moderately trained men, ${ }^{56}$ but there is little information on women. Changes in HDL-C responses unique to women after short duration exercise might be confounded because of the use of oral contraceptive agents, ${ }^{3}{ }^{12}$ different phases of the menstrual cycle, ${ }^{12}{ }^{13}$ gender specific lipolytic activity, ${ }^{14}$ and high baseline HDL-C levels. ${ }^{15}$

This study was undertaken to provide a controlled evaluation of the acute effects of moderate duration exercise on HDL-C and HDL-C subfractions in trained premenopausal women.

\section{Methods}

SUBJECTS

Twelve women runners were recruited from Mankato State University and the surrounding community to participate in this investigation. They were selected on the basis of the following criteria: 18-35 years of age (mean (SD) age 22 (4) years); running $24-48 \mathrm{~km}$ a week for a minimum of six months (35.7 (9.1) km/week); stable weight for at least six months (56.6 (7.1) $\mathrm{kg}$ ); no use of medications or oral contraceptives; no current use of alcohol; no medical conditions that would preclude them from participation. Mean percentage body fat, determined using hydrostatic weighing and the Siri equation, ${ }^{16}$ was 14.3 (6.6)\%. All participants reported regular menstrual cycles (27-32 days) for the previous six months. Each participant signed a written informed consent approved by the Institutional Review Board for Human Subjects. Subjects were given a health screening and oriented to running on a motor driven treadmill before participating.

EXPERIMENTAL DESIGN

On day 1 subjects underwent a graded exercise test on a motor driven treadmill to determine $\mathrm{VO}_{2} \mathrm{MAX}$. After a 15 minute period of rest, participants then ran on the treadmill to deter- 
Table 1 Four day dietary composition. Values are mean (SD)

\begin{tabular}{llllll}
\hline & Day 1 & Day 2 & Day 3 & Day 4 & Average \\
\hline Total energy (Kcal) & $1523(356)$ & $1718(286)$ & $1674(317)$ & $1605(410)$ & $1630(338)$ \\
Carbohydrate (\%) & $59(9)$ & $65(11)$ & $68(10)$ & $66(11)$ & $65(10)$ \\
Fat (\%) & $25(9)$ & $22(7)$ & $20(9)$ & $20(8)$ & $22(8)$ \\
Protein (\%) & $16(2)$ & $13(3)$ & $12(4)$ & $14(2)$ & $14(3)$ \\
P/S Ratio & $0.6(0.3)$ & $0.7(0.2)$ & $0.7(0.2)$ & $0.7(0.2)$ & $0.7(0.2)$ \\
\hline
\end{tabular}

$\mathrm{P} / \mathrm{S}$ ratio $=$ polyunsaturated $/$ saturated fat ratio

mine the work rate corresponding to $75 \%$ $\mathrm{VO}_{2} \mathrm{MAX}$.

One to two weeks later, on day 2 , subjects ran on a motor driven treadmill at $75 \% \mathrm{VO}_{2} \mathrm{MAX}$ until 3.34 MJ (800 kcal) was expended. Each subject was scheduled to perform the experimental trial during the early follicular phase (days 5-10) of their menstrual cycle since minimal lipid and lipoprotein variation occurs during this phase. ${ }^{12}{ }^{17}$ On day 2 subjects underwent a standard warm up run, at which time the treadmill speed was gradually increased until the appropriate power output (75\% $\mathrm{VO}_{2} \mathrm{MAX}$ ) was reached. This was accomplished by increasing the treadmill speed to 70,85 , and $100 \%$ of the predetermined running speed every other minute. The treadmill speed was adjusted to maintain the target intensity throughout the exercise trial. This was done if $\mathrm{VO}_{2}$ varied $\pm 2 \mathrm{ml} / \mathrm{kg}$ per minute from the target intensity.

During the exercise trial, cardiovascular and respiratory metabolic measures were recorded every minute. However, once steady state was ensured, subjects were allowed to remove the respiratory apparatus for seven minutes after every ten minutes of respiratory gas measurement. Respiratory gas measurements were obtained using a MedGraphics CPX metabolic system. Energy expenditure was calculated using the steady state respiratory exchange ratio and absolute $\mathrm{VO}_{2} \cdot{ }^{18} \mathrm{Cool}$ water was provided to subjects every ten minutes during the exercise trial.

To avoid dietary interaction with lipid measurements, each subject was asked to maintain their normal dietary habits and complete a four day food diary beginning two days before the experimental trial. Daily nutrient intakes were analysed by the Food Processor II nutritional software package from ESHA Research Inc.

BLOOD SAMPLING AND STORAGE

Venous blood samples were obtained at the following time points: baseline and immediately (IPE), one hour (1 h PE), 24 hours (24 h PE), and 48 hours ( $48 \mathrm{~h} \mathrm{PE}$ ) after exercise. All blood samples were taken after a $12 \mathrm{~h}$ fast from an antecubital vein with the subject in the seated position. Subjects abstained from exercise for 48 hours before the baseline measurement, to avoid any influence on baseline. Blood samples were collected into a $10 \mathrm{ml}$ heparinised tube. Plasma was analysed for total cholesterol, triglycerides, HDL-C, $\mathrm{HDL}_{2}-\mathrm{C}$, and $\mathrm{HDL}_{3}-\mathrm{C}$. The plasma samples were separated by low speed centrifugation and stored at $-70^{\circ} \mathrm{C}$ until analysis.

BLOOD ANALYSIS

All blood assays were performed in duplicate in a Centers for Disease Control reference laboratory by the same technician. Interassay variation was prevented by analysing all samples from each subject in a single batch run. Cholesterol ${ }^{19}$ and triglycerides ${ }^{20}$ were measured using enzymic methods on a Cobas Bio (Roche) Centrifugal Analyzer. HDL-C was determined after precipitation of lower density lipoproteins using heparin/ $\mathrm{MnCl}_{2}{ }^{21}$ The methods of Delong et $a l^{22}$ were used to calculate low density lipoprotein cholesterol (LDL-C) and very low density lipoprotein cholesterol (VLDL-C). High density lipoprotein (HDL) subfractions were determined using HDL 2/3 precipitation methods. ${ }^{23}$ Packed cell volume and haemoglobin were measured using a Coulter Counter model STKS from Coulter Electronics Inc. Changes in plasma volume were determined by the methods of Dill and Costill. ${ }^{24}$

\section{STATISTICAL ANALYSIS}

Results are all means (SD). Lipid and lipoprotein variables were analysed using one way analysis of variance with repeated measures. All values were corrected for changes in plasma volume. A Tukey HSD post hoc test was utilsed to test for differences between means. Values for each time point were compared with baseline values. $p<0.05$ was required for statistical significance.

\section{Results}

On day 2 subjects exercised for $72(9.8) \mathrm{min}$ at 73.4 (2)\% of $\mathrm{Vo}_{2} \operatorname{MAX}$ (41.1 (3.4) $\mathrm{ml} / \mathrm{kg}$ per $\mathrm{min})$. The subjects' total energy expenditure was 3.35 (0.01) MJ (801.4 (3.4)) kcal, completing a total distance of $12.2(2.1) \mathrm{km}$. The subjects' average daily diet consisted of 6.81 (1.4) MJ (1630 (338)) kcal and was comprised as follows: 65 (10)\% carbohydrate, 14 (3) $\%$ protein, and $22(8) \%$ fat. The mean polyunsaturated to saturated fat ratio was 0.7 (0.2). Diet composition was unchanged over the course of the experiment (table 1).

\section{UNCORRECTED FOR PLASMA VOLUME}

Significant differences in lipid and lipoproteins, uncorrected for changes in plasma volume, were observed over time (table 2). HDL-C at IPE was increased above baseline values $(p<0.01)$ but returned to baseline at $1 \mathrm{~h}$ PE. Similarly, $\mathrm{HDL}_{3}-\mathrm{C}$ was increased above baseline values at IPE $(p<0.01)$. However, no significant increase was observed in $\mathrm{HDL}_{2}-\mathrm{C}$. Plasma triglyceride values were significantly lower than baseline at $24 \mathrm{~h} \mathrm{PE}(\mathrm{p}<0.05)$ and 48 h PE $(p<0.05)$. As expected, VLDL-C replicated plasma triglyceride values $(p<0.05)$. No significant differences were observed between baseline and any other sampling point for total cholesterol or LDL-C.

\section{CORRECTED FOR PLASMA VOLUME}

Once corrected for post-exercise plasma volume shifts, significant lipid and lipoprotein changes were observed which differed from the uncorrected values. The calculated loss in plasma volume IPE was $4(6) \%(\mathrm{p}<0.05)$ (table $3)$. When the shift in plasma volume was 
Table 2 Uncorrected plasma lipid and lipoprotein responses after exercise in moderately trained females. Values are mean (SD)

\begin{tabular}{|c|c|c|c|c|c|}
\hline & \multirow{2}{*}{$\begin{array}{l}\text { Before exercise } \\
\text { Baseline }\end{array}$} & \multicolumn{4}{|l|}{ After exercise } \\
\hline & & $I P E$ & $1 h P E$ & $24 h P E$ & $48 h P E$ \\
\hline TC & $3.88(0.6)$ & $4.13(0.8)$ & $4.03(0.7)$ & $3.81(0.8)$ & $3.94(0.9)$ \\
\hline TG & $1.06(0.7)$ & $1.14(0.6)$ & $0.97(0.5)$ & $0.82(0.5)^{\star}$ & $0.81(0.4)^{\star}$ \\
\hline LDL-C & $2.08(0.6)$ & $2.09(0.7)$ & $2.08(0.7)$ & $2.02(0.7)$ & $2.09(0.8)$ \\
\hline VLDL-C & $0.42(0.3)$ & $0.43(0.2)$ & $0.36(0.2)$ & $0.3(0.18)^{\star}$ & $0.3(0.14)^{\star}$ \\
\hline HDL-C & $1.46(0.3)$ & $1.62(0.3)^{\star}$ & $1.56(0.4)$ & $1.53(0.3)$ & $1.54(0.3)$ \\
\hline $\mathrm{HDL}_{2}-\mathrm{C}$ & $0.67(0.3)$ & $0.64(0.3)$ & $0.7(0.4)$ & $0.7(0.27)$ & $0.73(0.3)$ \\
\hline $\mathrm{HDL}_{3}-\mathrm{C}$ & $0.8(0.14)$ & $0.98(0.2)^{\star \star}$ & $0.84(0.16)$ & $0.75(0.13)$ & $0.81(0.13)$ \\
\hline
\end{tabular}

All values are given as $\mathrm{mmol} / \mathrm{l}$. To convert cholesterol to $\mathrm{mg} / \mathrm{dl}$ divide by 0.02586 . To convert triglycerides to $\mathrm{mg} / \mathrm{dl}$ divide by 0.01129 .

TC, total cholesterol; TG, triglyceride; LDL, low-density lipoprotein; VLDL, very low density lipoprotein; HDL, high-density lipoprotein; C, cholesterol.

$\star$ Significant difference from baseline value $(\mathrm{p}<0.05)$.

$\star \star$ Significant difference from baseline value $(\mathrm{p}<0.01)$

Table 3 Corrected plasma lipid and lipoprotein responses after exercise in moderately trained females. Values are mean (SD)

\begin{tabular}{llllll}
\hline \multicolumn{5}{c}{$\begin{array}{l}\text { Before exercise } \\
\text { Baseline }\end{array}$} & \multicolumn{2}{l}{ After exercise } \\
\cline { 3 - 6 } & & & & & \\
\hline Plasma volume (\%) & - & $-4.1(6)^{\star}$ & $-0.54(7.3)$ & $6.6(6.8)^{\star}$ & $3.9(7.6)^{\star}$ \\
TC & $3.88(0.6)$ & $3.96(0.8)$ & $4.0(0.8)$ & $4.04(0.8)$ & $4.06(0.8)$ \\
TG & $1.06(0.7)$ & $1.09(0.5)$ & $0.95(0.4)$ & $0.86(0.5)$ & $0.84(0.4)$ \\
LDL-C & $2.08(0.6)$ & $2.0(0.7)$ & $2.06(0.7)$ & $2.13(0.6)$ & $2.15(0.7)$ \\
VLDL-C & $0.42(0.3)$ & $0.41(0.2)$ & $0.36(0.16)$ & $033(0.2)$ & $0.31(0.15)$ \\
HDL-C & $1.46(0.3)$ & $1.56(0.3)$ & $1.56(0.4)$ & $1.55(0.3)$ & $1.59(0.3)^{\star}$ \\
HDL $-C$ & $0.67(0.3)$ & $0.62(0.3)$ & $0.73(0.4)$ & $0.76(0.3)$ & $0.75(0.3)$ \\
HDL $_{3}$-C & $0.8(0.14)$ & $0.94(0.2)^{\star \star}$ & $0.83(0.1)$ & $0.8(0.1)$ & $0.84(0.1)$ \\
\hline
\end{tabular}

All values are given as mmol/l. To convert cholesterol to $\mathrm{mg} / \mathrm{dl}$ divide by 0.02586 . To convert triglycerides to $\mathrm{mg} / \mathrm{dl}$ divide by 0.01129 .

TC, total cholesterol; TG, triglyceride; LDL, low-density lipoprotein; VLDL, very low density

lipoprotein; HDL, high-density lipoprotien; C, cholesterol.

$\star$ Significant difference from baseline value $(\mathrm{p}<0.05)$.

$\star \star$ Significant difference from baseline value $(\mathrm{p}<0.01)$

accounted for, HDL-C significantly increased above baseline at $48 \mathrm{~h} \mathrm{PE}(\mathrm{p}<0.05)$.

Changes in HDL subfractions after exercise were similar to uncorrected values. $\mathrm{HDL}_{3}-\mathrm{C}$ increased IPE $(p<0.01)$ and returned toward baseline at $1 \mathrm{~h}$ PE. Furthermore, no significant differences were observed for $\mathrm{HDL}_{2}-\mathrm{C}$ over time $(\mathrm{p}=0.10)$. No other differences in plasma lipid or lipoproteins were observed between baseline and other sampling points.

\section{Discussion}

This study observed an immediate postexercise increase in HDL-C when uncorrected for plasma volume shifts. However, after adjusting for changes in plasma volume, we detected a significantly different HDL-C response. After exercise, the increase in HDL-C was observed at $48 \mathrm{~h} \mathrm{PE}(\mathrm{p}<0.05)$ (fig $1)$. These findings support the need to adjust for plasma volume to measure actual postexercise changes in HDL-C concentrations. Consequently, it appears that short term exercise lasting less than two hours in moderately trained premenopausal women results in a delayed increase in HDL-C concentrations.

Post-exercise increases in HDL-C have previously been reported in women after prolonged exercise bouts lasting more than two hours. ${ }^{10} 11$ However, investigations that have attempted to identify post-exercise HDL-C responses in women after shorter exercise bouts (less than two hours) have yielded equivocal results. ${ }^{25}{ }^{26}$ Many of the inconsistencies in short term post-exercise lipid and lipo-

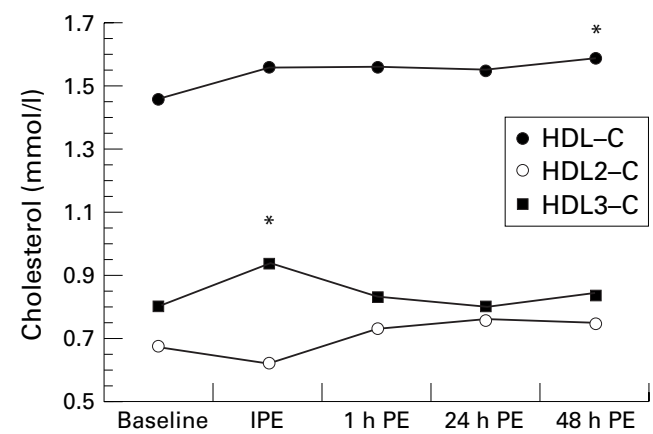

Figure 1 High density lipoprotein (HDL) cholesterol (HDL-C) and $H D L$ subfraction $\left(\mathrm{HDL}_{2}-\mathrm{C}, \mathrm{HDL}_{3}-\mathrm{C}\right)$ changes after acute exercise in moderately trained women. Measurements were made before exercise (baseline), or immediately (IPE), one hour (1 h PE), 24 hours (24 h $P E)$, or 48 hours (48 h PE) after exercise. ${ }^{\star} p<0.05 v$ baseline value.

protein alterations reported in women may be related, in part, to lack of control over confounding factors. Previous studies evaluating HDL-C responses in women after exercise lasting less than two hours either did not adjust the results for plasma volume ${ }^{25}$ or failed to correct for the change in red cell volume. ${ }^{26}$ Consequently, artificial changes in post-exercise lipid and lipoprotein modifications were probably recorded because of shifts in plasma volume. Additional variables that may potentially confound post-exercise HDL-C alterations in women may have also diluted the findings of previous studies. ${ }^{25-27}$ These include the use of oral contraceptives ${ }^{312}{ }^{26}$ and failure to control for the different phases of the menstrual cycle. $^{12}{ }^{13}$

Once these potential confounding factors are taken into account, the present findings are similar to those from previous studies utilising a similar research protocol $\left(75 \% \mathrm{VO}_{2} \mathrm{MAX}\right.$ until $3.34 \mathrm{MJ}$ expended) in male subjects, ${ }^{56}$ although the delayed increase in HDL-C reported in studies using men occurred at $24 \mathrm{~h}$ PE compared with $48 \mathrm{~h} \mathrm{PE}$ in the present study. Moreover, as in the present investigation, the male subjects had the same training level (24-48 km/week) and similar fitness levels (57.7 (5.2) $\mathrm{ml} / \mathrm{kg}$ per min for men compared with 56.3 (5) $\mathrm{ml} / \mathrm{kg}$ per min for women). As expected, however, baseline HDL-C concentrations were much higher $(\mathrm{p}<0.01)$ in the women $(56.5(11.5) \mathrm{mg} / \mathrm{dl})$ than the men $(41.4$ (6) $\mathrm{mg} / \mathrm{dl}$ ). Individuals with higher baseline HDL-C levels are thought to require a larger volume of work to elicit a post-exercise increase. ${ }^{3}$ Even though the women in the present study have higher baseline HDL-C values, it appears that, given comparable training status and fitness levels, similar postexercise HDL-C responses occur at this level of energy expenditure.

In the present study, a non-significant increase in HDL-C did occur IPE $(\Delta=3.9$ $\mathrm{mg} / \mathrm{dl}$ ) which stabilised across sampling time points until reaching significance at $48 \mathrm{~h} \mathrm{PE}(\Delta$ $=5 \mathrm{mg} / \mathrm{dl} ; \mathrm{p}<0.05)$. The rise in HDL-C IPE appeared in the $\mathrm{HDL}_{3}-\mathrm{C}$ subfraction $(p<0.01)$. However, we cannot rule out the possibility that the increase in $\mathrm{HDL}_{3}-\mathrm{C}$ may also be due, in part, to conversion of $\mathrm{HDL}_{2}-\mathrm{C}$ 
to $\mathrm{HDL}_{3}-\mathrm{C}$ (fig 1). We observed a nonsignificant decline in $\mathrm{HDL}_{2}-\mathrm{C}$ IPE which is not fully understood. Nevertheless, other investigators have reported transient increases in $\mathrm{HDL}_{3}-\mathrm{C}$ after shorter duration exercise (less than two hours) in women. ${ }^{26}{ }^{27}$ Moreover, studies involving short term exercise in men with the same training level and energy expenditure as in the present study have also reported similar post-exercise increases in $\mathrm{HDL}_{3}-\mathrm{C} . .^{5628}$ However, the time course for post-exercise increases in $\mathrm{HDL}_{3}-\mathrm{C}$ appeared different. For example, both Gordon $e t a l^{5}$ and Visich et $a l^{6}$ did not observe a post-exercise increase in $\mathrm{HDL}_{3}-\mathrm{C}$ until $24 \mathrm{~h} \mathrm{PE}$.

In contrast, $\mathrm{HDL}_{2}-\mathrm{C}$ was not significantly different across sampling points. However, a non-significant increase in $\mathrm{HDL}_{2}-\mathrm{C}$ occurred as $\mathrm{HDL}_{3}-\mathrm{C}$ began to decline at $1 \mathrm{~h} \mathrm{PE}$ (fig 1 ). In fact, by $48 \mathrm{~h}$ PE the change in HDL-C was more highly associated with an increase in $\mathrm{HDL}_{2}-\mathrm{C}(r=0.917 ; \mathrm{p}<0.001)$ than $\mathrm{HDL}_{3}-\mathrm{C}$ $(r=0.562 ; \mathrm{p}<0.05)$. This may exemplify the dynamic environment to which HDL subfractions exist. Berger et $a l^{29}$ first proposed that the esterification of free cholesterol by lecithin: cholesterol acyltransferase may be rate limiting, suggesting that additional time may be required for sufficient conversion of $\mathrm{HDL}_{3}-\mathrm{C}$ to $\mathrm{HDL}_{2}-\mathrm{C}$ to raise $\mathrm{HDL}_{2}-\mathrm{C}$ concentrations significantly. ${ }^{27} \mathrm{On}$ the basis of the present findings, we speculate that an acute exercise induced increase in $\mathrm{HDL}_{2}-\mathrm{C}$ may be controlled by a rate limiting lipolytic process and therefore may require more time to increase significantly above baseline.

The underlying biochemical mechanism responsible for acute increases in HDL-C after exercise is probably related to catabolism of triglyceride rich lipoproteins via lipoprotein lipase. ${ }^{6}$ Increased lipoprotein lipase activity after exercise results in chylomicron and VLDL hydrolysis and reductions in plasma triglyceride levels. ${ }^{3}$ Consequently, surface remnants are converted into nascent HDL-C. However, while HDL-C levels may increase after exercise, a concomitant decline in plasma triglyceride levels has not been consistently observed. Moreover, reductions in plasma triglyceride concentrations after acute exercise appear to be related to the amount of work completed. ${ }^{3}$ Exercise studies of women taking part in events that require a high energy expenditure-for example, triathlon-have reported decreased plasma triglyceride levels 24 $\mathrm{h}$ after exercise. ${ }^{911}$ In contrast, shorter durations of exercise may result in only modest decreases in plasma triglyceride ${ }^{27}$ or no change at all. ${ }^{26}$ In the present study, once values were corrected for changes in plasma volume, triglyceride levels at $48 \mathrm{~h} \mathrm{PE}$ were no longer significantly different from baseline $(\mathrm{p}=$ $0.06)$. However, the average decline in plasma triglyceride concentrations at $48 \mathrm{~h} \mathrm{PE}$ was $21 \%$ and was similar to observations in men performing the same volume of exercise ${ }^{6}$ Furthermore, the decline in plasma triglyceride observed in the present study, while not statistically significant, probably has clinical ramifications for HDL-C improvements.
In summary, it appears that an exercise bout of less than two hours in duration can elicit post-exercise increases in HDL-C in moderately trained premenopausal women. Although women have higher baseline HDL-C values than men, a similar delayed increase can be observed provided that training status and amount of exercise performed is equivalent. In addition, post-exercise modifications in HDL subfractions may be more dynamic in women than men. However, the exact mechanisms responsible for these alterations in lipolytic activity requires further investigation.

1 Miller NE. Associations of high-density lipoprotein subclasses and apolipoproteins with ischemic heart disease and coronary atherosclerosis. Am Heart f 1987;2:589-97.

2 Salonen TJ, Salonen R, Seppanen K, et al. HDL, HDL2 and HDL3 subfractions and risk of acute myocardial infarction. Circulation 1981;84:129-39.

3 Durstine JL, Haskell W. Effects of exercise training on plasma lipids and lipoproteins. Exerc Sport Sci Rev 1994;477-521.

4 Kantor MA, Cullinane EM, Sady SP, et al. Exercise acutely increases high density lipoprotein-cholesterol and lipoprotein lipase activity in trained and untrained men. Metabolism 1987;36:188-92.

5 Gordon PM, Goss FL, Visich PS, et al. The acute effects of exercise intensity on HDL-C metabolism. Med Sci Sports Exerc 1994;26:671-7.

6 Visich P, Goss F, Gordon P, et al. The effect of caloric expenditure on acute changes in high density lipoprotein cholesterol and high density lipoprotein subfractions. Eur $\mathcal{F}$ Appl Physiol 1996;72:242-8.

7 Kantor MA, Cullinane EM, Herbert PN, Thompson PD. Acute increase in lipoprotein lipase following prolonged Acute increase in lipoprotein lipase

8 Thompson PD, Cullinane E, Henderson LO, Herbert PN. Acute effects of prolonged exercise on serum lipids. Metabolism 1980;29:662-5.

9 Farber H, Arbetter J, Schaeffer E, et al.Acute metabolic effects of an endurance triathlon. Annals of Sports Medicine 1987;3:131-8.

10 Goodyear LJ, Van Houten DR, Fronsoe MS, et al. Immediate and delayed effects of marathon running on lipid and lipoproteins in women. Med Sci Sports Exerc 1990;22:58892.

11 Lamon-Fava S, McNamara JR, Farber H, et al. Acute changes in lipid, lipoprotein, apolipoprotein and lowdensity lipoprotein particle size after an endurance density lipoprotein particle size
triathlon. Metabolism 1989;38:921-5.

12 Pronk NP. Short term effects of exercise on plasma lipids and lipoproteins in humans. Sports Medicine 1993;16:43148.

13 Jones DY, Judd JT, Taylor P, et al. Menstrual cycle effects on plasma lipids. Metabolism 1988;37:1-2

14 Haskell WL, Stefanick ML, Superko R. Influence of exercise on lipids and lipoproteins. In: Horton ES, Terjung RL, eds. Exercise, nutrition and energy metabolism. New York: Macmillan, 1988:213-27.

15 Stefanick M, Wood P. Physical activity, lipid and lipoprotein metabolism, and lipid transport. In: Bouchard C, Shephard R, Stephens T, eds. Physical activity, fitness, and health: inter$\mathrm{R}$, Stephens T, eds. Physical activity, fitness, and health: international proceedings and consens
IL: Human Kinetics, 1994:418.

IL: Human Kinetics, 1994:418.
Siri WE. Body composition from fluid spaces and density: analysis of methods. In: Techniques for measuring body composition. Washington, DC: National Academy of Science, National Research Council, 1961:223-44.

17 Barclay M, Barclay R, Skipski V, et al. Fluctuations in human serum lipoproteins during the normal menstrual cycle. Biochem ₹ 1965;96:205-9.

18 McArdle W, Katch F, Katch V. Exercise physiology. 3rd ed. Malvern, PA: Lea \& Febiger, 1991:153.

19 Allain C, Poon L, Chan C. Enzymatic determination of total serum cholesterol. Clin Chem 1974;20:470-5.

20 Bucolo G, David H. Quantitative determination of serum triglycerides by the use of enzymes. Clin Chem 1973;19: $476-82$.

21 Department of Health, Education, and Welfare. Manual of laboratory operations: lipid and lipoprotein analysis. Washington DC: Department of Health, Education, and Welfare, 1974; publication no NIH 75-628, vol 1:57-8.

22 Delong DM, Delong ER, Wood PD, et al. A comparison of methods for the estimation of plasma low- and very low-density lipoprotein cholesterol: The Lipid Research Clinics Prevalence Study. FAMA 1986;256:2372-7.

23 Gidez L, Miller G, Burstein M, et al. Separation and quantitation of subclasses of human plasma high density lipoproteins by a simple precipitation procedure. $\mathcal{F}$ Lipid Res 1982;23:1206-23.

24 Dill DB, Costill DL. Calculation of percentage changes in volumes of blood, plasma, and red cells in dehydration. $f$ Appl Physiol 1974;37:247-8. 
25 Lennon DF, Stratman E, Shrago F, et al. Total cholesterol and HDL-cholesterol changes during acute moderateand HDL-cholesterol changes during acute moderateintensity

26 Swank A, Robertson R, Dietrich R, Bates M. The effects of acute exercise on high density lipoprotein cholesterol and the subfractions in females. Atherosclerosis 1987;63: $187-92$.

27 Lee R, Nieman D, Raval R, et al. The effects of acute mod- erate exercise on serum lipids and lipoproteins in mildly obese women. Int 7 Sports Med 1991;12:537-42.

28 Angelopolous TJ, Robertson RJ, Goss FL, et al. Effect of repeated exercise bouts on high density lipoproteincholesterol and its subfractions HDL2-C and HDL3-C. Int f Sports Med 1993;14:196-201.

29 Berger G, Griffiths $M$. Acute effects of moderate exercise on plasma lipoprotein parameters. Int. F. Sports Med 1987;8: 336-41.

\section{Musings of a running "agony aunt"}

Although the learned researchers and clinicians who have their offerings published in the British fournal of Sports Medicine probably do not realise it, much of their material is relatively unintelligible to the general public. Yet if you scan the book stalls, sports magazines abound, and many include medical and injury columns together with the obligatory "Agony Aunt" to satisfy the need for definitive advice on sport and exercise medicine.

Although it may seem easy for a doctor writer to fill the pages of a magazine with precis of interesting research, cautionary tales, and simple common sense, pitfalls abound. In the early 1980s, when people only wanted to run marathons and any other distance was considered soft, queries came from men with broken legs who had only one ambition in life - to run a marathon-when could they? Doubts begin to surface, however, as one realises that there is a considerable responsibility, both to the reader and their medical advisers, in replying. Should the exfootballer, already missing part of a meniscus, be warned that running high mileages on tarmac could aggravate his knee condition, and what of the lady who vomits at the three mile mark of every run, then can run for ever? Is it pathological or psychological?

Having read the closely written pages of A4, often with detailed training schedules and racing programmes, sometimes with an action photo thrown in, one has to appreciate the desperation with which some of these letters are written. Most have already sought medical advice and met with varying degrees of disinterest, incomprehension, trivialisation, and sometimes - only having received a highly subjective account of the problemwhat appears to be an arrogant dismissiveness by the profession that the enquirer should never have entertained hopes of competing or running after injury. While it is all too easy to criticise the obsession and introspection with which these people view their sport, to many it is not only a hobby and an escape, but their whole social life. Replying tactfully in order not to exacerbate differences between patient and doctor can require the skills of a Kissinger on occasions.

Many have received advice that is totally negative, and seek a second opinion. One has to be guarded in one's answers, for, although the runner whose myopic retina detached in a race really is at risk of a recurrence, the MI victim may benefit his coronary arteries through a graduated training programme, although this really ought to be under the guidance of a cardiologist after full investigation and counselling, most of which is outside the scope of a written and published reply.

The postbag confirms that injured sportsmen feel that they do not receive the urgent priority care that their injuries merit. Whether they are more poorly treated than other sections of the population is another debate. What is undoubtedly true is that they feel there is neither the interest nor very often the local ability to understand and treat their problems. Much of their frustration is the result of a high degree of motivation which tempts some to overdo the therapeutic processes.

Finally, what of the letter I received from a lady about to have a reduction mammoplasty, as the offending objects were slowing her running down. Would this operation affect her centre of gravity and therefore cause injury, she wanted to know? Answers please on a plain postcard!

PATRICK MILROY Dr Milroy has been the medical advisor to Runners World since 1982. 